\title{
The Construction of Physical Education Curriculum Assessment System Based on Computer Evaluation Technology
}

\author{
Haixia Li , Ruiyun Zhang \\ Department of Sports Social Science, Shandong Sport University, Jinan, China \\ School of Sports Arts, Shandong Sport University, Jinan, China
}

Keywords: computer evaluation; physical education; course evaluation; B / S framework; C / S framework; Java programming

\begin{abstract}
With the development of computer technology and the improvement of physical education teaching evaluation method, evaluation of sports courses can be realized by the computer. In the background of new education reform, teaching methods have undergone a lot of change. Physical education belongs to the action exemplary teaching. In the process of physical education, it needs to achieve the real-time information exchange between teachers and students which can improve teaching efficiency and effect. Based on this, the paper designs and develops the B / S and $\mathrm{C} / \mathrm{S}$ joint computer frame mode of physical education curriculum assessment and established the mathematical model of the physical education curriculum assessment using the comprehensive fuzzy evaluation theory. Finally, the paper prepares programming language of the physical education curriculum assessment system through Java programming and the expert weight coefficient of PE curriculum evaluation. It also designs computer evaluation system of physical education curriculum assessment which provides a theoretical reference for PE curriculum assessment system.
\end{abstract}

\section{Introduction}

Since the introduction of the new education reform, major colleges and universities continue to change the teaching objectives and teaching modes and innovates teaching methods and achieve the goal of the new education reform [1,2]. Physical education is also a focus of the new education reform. The development of sports related to health and physical development of each student. Evaluation of the effectiveness of the physical education not only can evaluate the teaching effectiveness of teachers reasonable which can make the teachers change the teaching methods but also is the basis of policy-making of encouraging physical education [3]. A fair and reasonable physical education curriculum assessment method can improve teaching efficiency and effect. This paper designed computer B / S framework and C / S framework evaluation system of physical education curriculum assessment using the Java programming language. It also achieved comprehensive fuzzy evaluation of courses successfully through the system which provides a theoretical method for the development of physical education curriculum.

\section{Introduction of Physical Education Courses Computer Evaluation System}

Student-centered teaching idea of the new education reform becomes important teaching ideology of teachers in the teaching process. Student-centered idea must respect each student. Real-time interaction between teachers and students in the teaching process must be implemented. Only in this way, teachers can understand the evaluation of each student and students can also choice the teachers who teach them in the physical education curriculum reasonable [4,5]. According to this idea, this paper designed computer evaluation system of physical education curriculum assessment. The specific schematic diagram is shown in Figure 1.

Figure 1 is the diagram of sports computer evaluation system. From the Figure, we can see that the main function of the system include curriculum evaluation of students on teachers, online 
examination, papers correction, the view of student's feedback and assessment [6]. System maintenance in the evaluation process needs to operate by administrator.

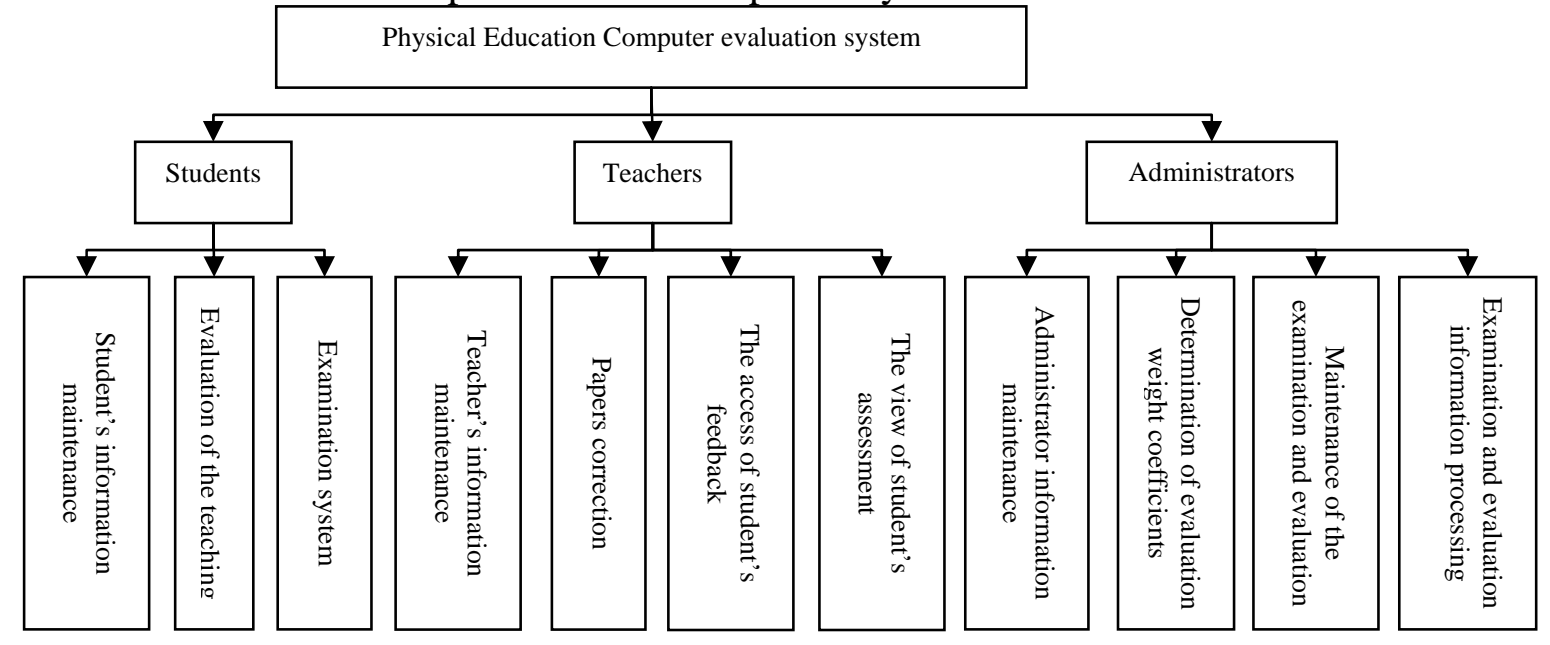

Figure 1. Diagram of sports computer evaluation system

\section{Mathematical model of computer evaluation of physical education courses}

Fuzzy mathematics method is a mathematical model commonly used in the evaluation system. The PE curriculum assessment related to a variety of indicators and it is suitable to fuzzy mathematical evaluation method [7,8]. Fuzzy mathematical methods can represent a variety of indicators of the physical education curriculum evaluation using the form of matrix. Weight coefficients of various indicators can be determined based on the teaching evaluation experts and the students' evaluations. Physical education computer evaluation model can be established which is evaluates the physical training.

Assuming that physical education curriculum assessment has b aspect, matrix form of physical education curriculum evaluation can be written as equation (1):

$$
\mathrm{X}=\left\{x_{1}, x_{2}, \cdots, x_{\mathrm{b}}\right\}
$$

If the evaluation results can be divided into c grades, results matrix of physical education curriculum evaluation can be written as equation (2):

$$
\mathrm{Y}=\left\{y_{1}, y_{2}, \cdots, y_{\mathrm{c}}\right\}
$$

In order to achieve the comprehensive evaluation of PE curriculum, we need to evaluate the Physical Education curriculum from every specific aspect. The evaluation result indicates the degree of membership of the overall results of the evaluation. The membership matrix of evaluation can be expressed as equation (3):

$$
\mathrm{D}=\left(\begin{array}{cccc}
d_{11} & d_{12} & \cdots & d_{1 n} \\
d_{21} & d_{22} & \cdots & d_{2 n} \\
\vdots & \vdots & \ddots & \vdots \\
d_{b 1} & d_{b 2} & \cdots & d_{b n}
\end{array}\right)
$$

Among them, $d_{i j}$ can be obtained using equation (4): 
$d_{r t}=\left\{\begin{array}{l}1,(r=t) \\ 1-w \sum_{u=1}\left|x_{r u}-x_{t u}\right|,(r \neq t)\end{array}\right.$

Comprehensive fuzzy evaluation matrix can be represented by the formula (5):

$\mathrm{Z}=\mathrm{X} \cdot \mathrm{D}=\left(x_{1}, x_{2}, \cdots, x_{b}\right)\left(\begin{array}{cccc}d_{11} & r_{12} & \cdots & r_{1 n} \\ r_{21} & r_{22} & \cdots & r_{2 n} \\ \vdots & \vdots & \ddots & \vdots \\ r_{b 1} & r_{b 2} & \cdots & r_{b n}\end{array}\right)=\left(q_{1}, q_{2}, \cdots, q_{n}\right)$

The judgment of the rates of the evaluation results can be obtained by the following equation:

$$
\mathrm{P}=\frac{\sum_{\mathrm{t}=1}^{\mathrm{n}} \mathrm{b}_{\mathrm{t}}^{\mathrm{u}} \cdot t}{\sum_{t=1}^{n} b_{t}^{u}}
$$

\section{The design of physical education course evaluation system based on computer evaluation technique}

The new education reform requires that the teaching process should treat the student as the center. Teachers and students must maintain the real-time interaction in the teaching process [9]. Traditional computer teaching evaluation system general is the C/S framework mode which is a closed teaching evaluation mode and cannot achieves the real-time interaction of teachers and students. According to the purposes of new education reform, this paper developed an open-PE curriculum assessment computer evaluation system-- teaching evaluation system controlled by B/S and C/S. Through the system, students can see and evaluate the evaluation results and the teaching effectiveness of the teachers. Teachers can see real-time feedback of students and achieve the real-time interaction of the teachers and students. The specific design of the framework is shown in Figure 2.

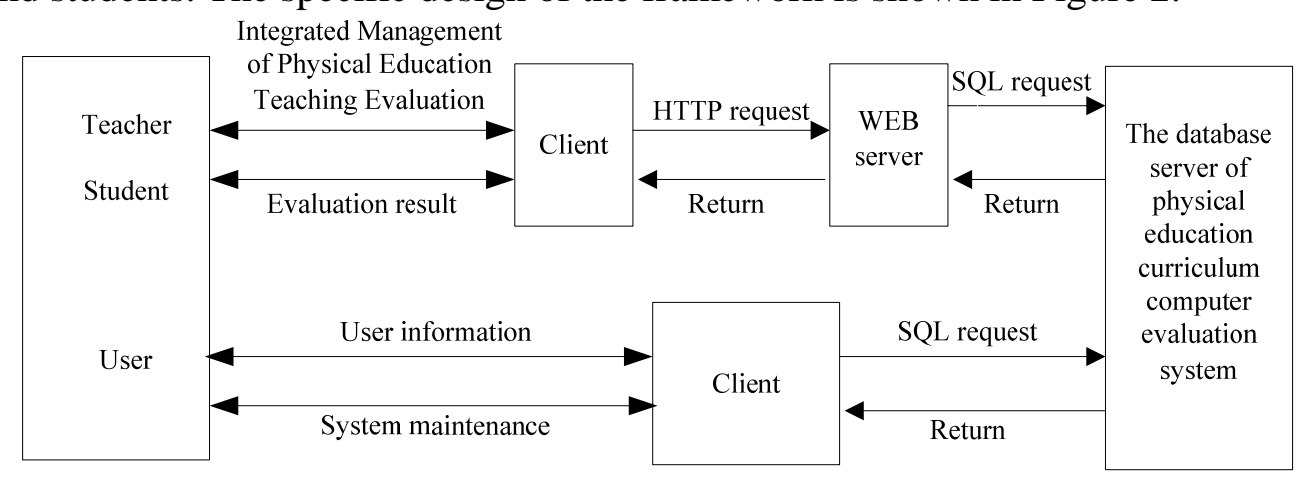

Figure 2. The joint frameworks of B / S and C / S of physical education curriculum evaluation

Figure 2 is the computer physical education curriculum evaluation system using the joint framework form of the B / S and C/S. This form not only realizes the interaction of both teachers and students in real time but also reduces data redundancy caused C/S closed-loop mode and improves the efficiency of the maintenance of computer WEB. It is a more secure and reliable computer evaluation system.

Figure 3 is the schematic diagram of computer evaluation process of physical education curriculum. From the Figure, we can see that there will produced a series of results when the students submit the teaching evaluation [10]. We can evaluate these results through computer evaluation 
system using the principle of fuzzy comprehensive evaluation and calculate the final results of the evaluation.

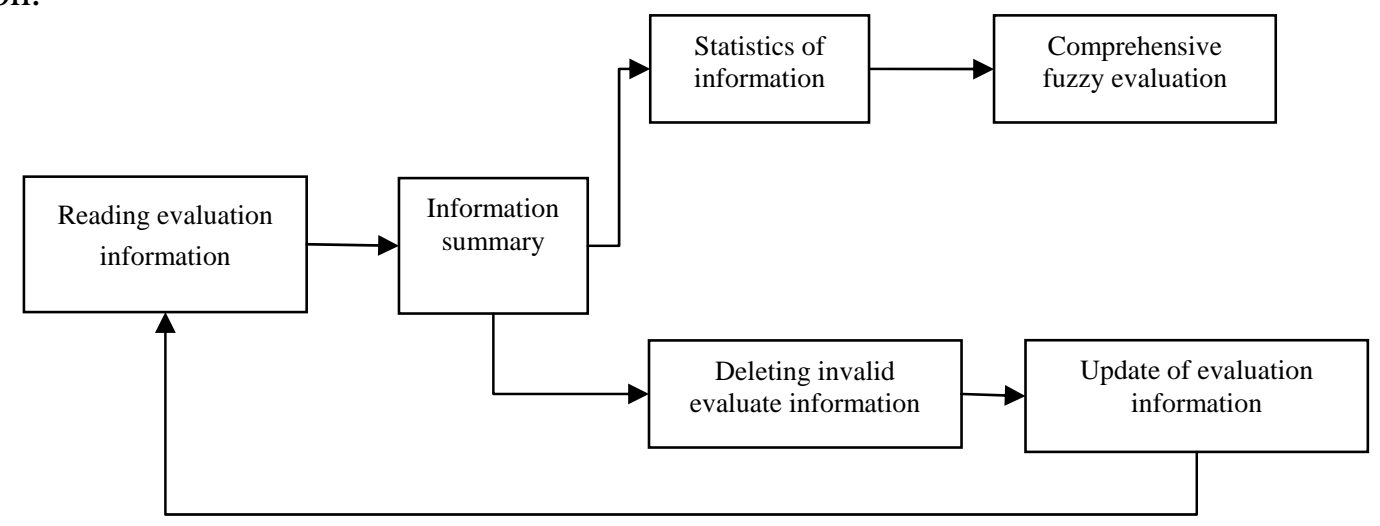

Figure 3. The schematic diagram of computer evaluation process of physical education curriculum

Table 1 is the table of physical education curriculum evaluation index weight concluded by the evaluation experts and student assessment statistics. Student assessment information can be summarized through computer programming which input the evaluation weight into evaluation system and comprehensive fuzzy evaluation mathematical model [11]. In order to achieve the computer evaluation of PE curriculum, this paper does the language design on the comprehensive fuzzy evaluation program through the way of the Java programming.

TABLE I. TABle TyPE Styles

\begin{tabular}{|c|l|l|l|}
\hline \multirow{2}{*}{$\begin{array}{c}\text { Table } \\
\text { Head }\end{array}$} & Table Column Head & Subhead & Subhead \\
\cline { 2 - 4 } & Table column subhead & \\
\hline copy & More table copy $^{\mathrm{a}}$ & & \\
\hline
\end{tabular}

Through the programming control, the window of evaluation structural data table can be concluded as follows:

\begin{tabular}{|c|c|c|c|}
\hline Column Name & Datatype & 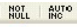 & Flags \\
\hline$?$ tid & Es INTEGER & $\checkmark$ & $\checkmark$ UNSIGNED $\square$ ZEROFILL \\
\hline$\varphi$ tname & I) VARCHAR(32) & $\checkmark$ & $\square$ BINAFYY \\
\hline$\varphi$ count & ES INTEGER & $\checkmark$ & $\square$ UNSIGNED $\square$ ZEROFILL \\
\hline$\diamond n$ & $3 \mathrm{VARCHAR(6)}$ & $\checkmark$ & $\square$ BINARYY \\
\hline$\Delta 12$ & VARCHAB(G) & $\checkmark$ & $\square$ BINARY \\
\hline 013 & (3) VARCHARI(B) & $\checkmark$ & $\square$ BINARY \\
\hline$\diamond 14$ & VARCHAB:(6) & $\checkmark$ & $\square$ BINARY \\
\hline$\diamond 15$ & S VARCHAR(6) & $\checkmark$ & $\square$ BINARY \\
\hline$\odot$ recard & 3) VARCHÄ.R(45) & $\checkmark$ & $\square$ BINARY \\
\hline$\theta$ td 1 & (3) VARCHAR(20) & $\checkmark$ & $\square$ BINARY \\
\hline$Q \mathrm{Id} 2$ & I8 VARCHAR(20) & $\checkmark$ & $\square$ BINARY \\
\hline$\theta$ id 3 & (6) VARCHARI20) & $\checkmark$ & $\square$ BINARY \\
\hline$\Leftrightarrow$ id 4 & (3) VARCHAR(20) & $\checkmark$ & $\square$ BINARY \\
\hline$\Delta \mathrm{td} 5$ & I8 VARCHAR(20) & $\checkmark$ & $\square$ BINARY \\
\hline$\diamond \mathrm{td} 6$ & I) VARCHAR(20) & $\checkmark$ & $\square$ BINARY \\
\hline$\Leftrightarrow$ idf & 8 VARCHAR $(20)$ & $\checkmark$ & $\square$ BINARY \\
\hline
\end{tabular}

Figure 4. The schematic diagram of evaluation result of the data structure table

Figure 4 shows the data structure table of evaluation results. The contents which can be achieved in the data table are the names of teachers and students and the number of students and score and the message of each evaluation. Final physical education course evaluation result can be concluded through the summary of results.

\section{Conclusion}

This paper analyzed and researched physical education curriculum evaluation system according to the principle of computer evaluation technique. The first part introduced the physical education curriculum evaluation system this thesis designed the function of the system. The second part of the paper established the mathematical model of the teaching model of physical education through a comprehensive fuzzy evaluation theory and introduced comprehensive fuzzy evaluation matrix form. The third part designed B / S and C / S joint framework model of computer evaluation of PE curriculum combined with comprehensive fuzzy evaluation mathematical model. Finally, this paper designed the Java programming language taking the evaluation of the students about physical 
education course for example and concluded the implementation form of the data structure table and designed the physical training computer evaluation system.

\section{References}

[1] Yongbi Li. Demand analyze of teaching evaluation system based on network technology [J]. Digital technology and application, 2010(10): 43-44.

[2] Jianbo Wang. Research on the teaching quality safeguards system of vocational colleges [J]. Ningbo University (Educational Science Edition), 2010 (2): 126-129.

[3] Suling Gao. Education quality evaluation system of the higher vocational college [J]. Henan Vocational and Technical Teachers College (Vocational Education Edition), 2010 (6): 16-18.

[4] Hong Xu. Demand system on educational administration network system based on B / S structure [J]. Huaiyin Institute of Technology, 2011(10): 21-22.

[5] Hongmei Chen. Design and Implementation of student's management system [J]. Computer Learning, 2010 (3): 25-27.

[6] Weimin Li, Lin Yang. The dynamic implementation of the addition of the drop-down menu based on the SQL Server database [J]. The computer learning, 2011 (l): 42-43.

[7] Xinyin Zhang. ASP.NET basis and comments of case's development [J]. Beijing: Tsinghua University Press, 2010(03): 32-33.

[8] Banggui Xia. The design and implementation of library management system based on the ADO [J]. Modern computer .2009 (4):178-180.

[9] Laixi Zhang, Shuxiang Li. The construction of development quality evaluation index system of vocational colleges [J]. Development and innovation of machinery and electronic products, 2010(1): 182-184.

[10]Weichun Li. Design and Implementation of B/S mode electronic reporting system [J]. Computer Development \& Applications, 2010 (7): 21-22.

[11]Linhua You. Multi-condition and multi-table query statistics of SQLServer under ASP [J]. Computer Programming Skills \& Maintenance, 2011 (12): 47-49.

TABLE II. FUZZY EVALUATION INDEX WEIGHT TABLE

\begin{tabular}{|c|c|c|c|c|c|}
\hline $\begin{array}{c}\text { Physical } \\
\text { education } \\
\text { attitude }\end{array}$ & $\begin{array}{c}\text { Sports } \\
\text { action } \\
\text { demonstra } \\
\text { tion }\end{array}$ & $\begin{array}{c}\text { Sports } \\
\text { innovative } \\
\text { approach }\end{array}$ & $\begin{array}{c}\text { Sports } \\
\text { research and } \\
\text { teaching }\end{array}$ & $\begin{array}{c}\text { Sports } \\
\text { action } \\
\text { standard }\end{array}$ & $\begin{array}{c}\text { Classroom } \\
\text { teaching task of } \\
\text { physical } \\
\text { education }\end{array}$ \\
\hline 0.05 & 0.15 & 0.18 & 0.05 & 0.25 & 0.32 \\
\hline
\end{tabular}

